\title{
FIOS DO DISCURSO PREDOMINANTE NO CURRÍCULO: LÍNGUA PORTUGUESA NO ENSINO FUNDAMENTAL ${ }^{1}$
}

\section{STRINGS OF DISCOURSE PREDOMINANT OF CURRICULUM: PORTUGUESE LANGUAGE IN INTERMEDIATE LEVEL}

Valda Inês Fontenele Pessoa

\section{RESUMO:}

$\mathrm{O}$ artigo tem como objetivo analisar narrativas de aluno/as do quinto período do curso de Letras Português da Universidade Federal do Acre, sobre aspectos sócioculturais e pedagógicos do ensino de Língua Portuguesa de escolas de Rio Branco. 0 texto é descritivo analítico, com o propósito de desnaturalizar percepções sobre a prática pedagógica das escolas observadas. Os dados foram coletados por meio de observações produzidas em narrativas a partir das vivências no componente curricular de Estágio Supervisionado. Das narrativas escritas, foram extraídos quatro fragmentos para a análise, subsidiando a escrita do artigo que ora apresentado. Foram inseridas abordagens de diferentes campos que contribuem com a construção do mosaico interpretativo, principalmente Giroux (1997); Hall (1997); Possenti (1995 e 1996) e Popkewits \& Lindblad (2016).

\section{PALAVRAS-CHAVE:}

Ensino. Currículo. Avaliação. Estatística. Língua Portuguesa.

\section{ABSTRACT:}

The article aims to analyze student narratives from the fifth period of the Portuguese Course of the Universidade Federal do Acre on social, cultural and pedagogical aspects of the Portuguese Language teaching of Rio Branco schools. The text is descriptive analytical, with the purpose of denaturalizing perceptions about the pedagogical practice of the observed schools. The data were collected through observations, produced in narratives, based on experiences in the curricular component of Supervised Stage. From the written narratives, four fragments were extracted for the analysis, subsidizing the writing of the article that now becomes public. For the analysis, thinkers from different fields were brought in to cross paths that contribute to the construction of the interpretive mosaic, mainly Giroux (1997); Hall (1997); Possenti $(1995 ; 1996)$ and Popkewits and Lindblad (2016).

\section{KEYWORDS:}

Teaching. Curriculum. evaluation. Statistic. Portuguese Language.

1 Uma versão inicial deste artigo foi apresentada em comunicação oral no XI Simpósio de Linguagens e Identidades da/na Amazônia Ocidental/I Seminário Internacional de Estudos Linguísticos e Literários das Amazônias e II Seminário de Humanidades: Licenciaturas, no período de 20 a 24 de novembro de 2017 - Universidade de Rondônia, com o título Estágio supervisionado do curso de letras português: narrativas de alunos sobre o discurso predominante da escola.

2 Doutora em Educação pela Pontifícia Universidade Católica de São Paulo (2011) e Professora da Universidade Federal do Acre, lotada no Centro de Educação, Letras e Artes. 
...talvez seja hora de tentar trabalhar no campo pedagógico pensando e escrevendo de uma forma que se pretende indisciplinada, insegura e imprópria.

Larrosa (2015).

\section{Preâmbulo aos fios da tecedura}

Ade pensar e escrever tem imprimido em nóscerto fascínio há algum tempo, mas sistematicamente desencorajada porconcepções epistemológicas produzidas por princípios predominantes da modernidade, que têm orientado a construção do conhecimento. No entanto, a partir da experiência do doutoramento, o receio imposto pelas formas estruturadas, impeditivas dehíbridos, foi se tornando menos intenso, permitindo alçar o pensamento e a escrita em outros patamares. Temos nos dado o prazer de transitar nesse universo sem grandes certezas, mas com leveza (BAUMAN, 2001) e muita vontade de compreender a diversidade dos discursos que rodeiam e constroem o fazer das escolas públicas amazônicas, em especial do município de Rio Branco, no estado do Acre.

Aos moldes de Fazenda (2006), Garcia (2000) e Alves (2008); aprendemos que pela fronteira do cotidiano das práticas da docência com as práticas de pesquisa e pelas fronteiras que separam os campos de conhecimentos, podemos alcançar um ângulo de visão muito mais amplo, mesmo sabendo que não enxergamos todos os fios que entrelaçam e conformam os discursose significações. No entanto, desses pressupostos decorre a pertinência da prudência, companheira inseparável, que aguça a humildade diante das nossas percepções sobre os objetos das nossas análises, nos mantendo alertas àscertezas e crenças generalistas, próprias das construções da modernidade, que nos impregnaram ao longo da formação para a docência e que, no momento contemporâneo, tentamos desconstruir. Àqueles que transitam à vontade no discurso da modernidade, pode parecer desconfortável as 
metáforas que buscamos para tecermos o texto. Entretanto, esse tem sido o contínuo exercício para nos afastarmos da escrita icônica considerada científica, possibilitando outras formas menos convencionais.

\section{Atravessando fronteiras no caminho e os propósitos da tecedura dos fios}

$\mathrm{Na}$ condição de docente, pesquisadora e eterna estudante, à medida que adentramos em outros campos disciplinares; aprendemosque as certezas não são tão certas comonos induziram a pensar; que as verdades teóricas, às quais fomos tendo contato, não são tão verdadeiras para todos, em qualquer situação e em qualquer contexto como são disseminadas pelas generalizações; que a ciência se fez - se faz e se refaz por meio das rupturase que é um espaço feroz de poder para manter a última verdade; que a objetividade de qualquer produção de conhecimento passa pelo processo de significação e de sentidos, construídos pelos grupos de pesquisadores com convicções epistemológicas diferenciadas, mas que não são impedidas de comunicação.

Assim, nessas contínuas produções e aprendizagens rizomáticas, fomos tecendo e datandoas nossas ações no cotidiano de professora e pesquisadora, construindo e reconstruindo fazeres, abertas a novos conhecimentos, sempre com a intensão de tornar o ângulo de visão o mais amplo possível, alargando as margens de movimentação para o que encontramos a cada semestre letivo, junto aos nossos alunos e dessa forma, diminuir a nossa corcunda de especialista do campo da educação e em especial do campo do currículo (GALLO, 2004). Em nossas incursões por outros campos do conhecimento, temos aprendido como melhor atuar pedagogicamente nas aulas dos componentes curriculares na graduação e na pós-graduação,sempre imbuída da pretensão de tornar os encontros plenosde aprendizagens.Com a atenção voltada para a pluralidade das 
salas de aula, vamos puxando um fio aqui outro ali, transpondo fronteiras e nos permitindo indisciplinadamente tomar de outros por empréstimo o que eles criaram e nos apresentaram benevolamente, tornando possíveis ações que têm permitido avançar nas compreensões dos fenômenos que se apresentam.

Em Foucault (2007), aprendemos a desconstruir concepções consolidadas ao longo de uma trajetória de formação, que aos pouco foram se liquidificando (BAUMAN, 2001), deixando de ser tão sólidas e fixas como nos fizeram crer. Com Hall (1997), percebemos que os sujeitos são seres interpretativos, instituidores de sentidos e que a ação social é significativa tanto para aqueles que as praticam quanto para os que as observam e que nem sempre são coincidentes. Dessa forma, as ações sociais, nelas incluídas, as de ensinar e de pesquisar, não se repetem em si mesmas. Pelo contrário, se estabelecem a partir dos sujeitos plurais, que trazem consigo sistemas de significação também plurais, os quais utilizam para definir coisas, ações e relações, codificando, organizando e regulando suas condutas, uns em relação aos outros. Tais sistemas ou códigos, tomados em seu conjunto formam as diversas culturas. Ou melhor, esses sistemas ou códigos de significados, contribuem para assegurar que toda ação social é "cultural", que todas as práticas sociais expressam ou comunicam um significado e, nesse sentido, são práticas de significação (HALL, 1997, p. 16). Destarte a essa compreensão, decorre o peso epistemológico que esse pensador dá à cultura, colocando-a como central na estrutura empírica da pesquisa e na criação e organização de qualquer atividade.

Por outro lado, dentro do campo do currículo, aprendemos, com Giroux (1986), o conceito de resistência. Suas argumentações sugerem vicissitudes que podem superar o pessimismo e o engessamento dasabordagens 
teóricas da reprodução, construindo o conceito de pedagogia da possibilidade. Acredita na possibilidadede mediações e ações que possam agir contra as determinações de controle. "Segundo o autor, é possível direcionar o potencial de resistência de estudantes e de professore/as para um currículo que detenha conteúdos claramente políticos e que estabeleçam críticas às crenças e aos arranjos sociais dominantes" (PESSOA, 2016).

É por meio das mediações pedagógicas que nascem as possibilidades de resistência e de desconstrução, fazendo com que aluno/as percebam o papel de controle exercido interno e externamente à escola. Os currículos das escolas podem ser desenvolvidos aos moldes de uma esfera pública democrática, na qual os sujeitos possam exercitar a discussão, a participação e o questionamento, construindo e descontruindo alternativas. Nessas circunstâncias, o professor/aassume o papel de intelectual que busca a transformação, substituindo o papel reprodutivo de mero técnico especializado no contexto da burocracia escolar, mantendo-se envolvido com liberdade, livre de amarras e convenções, combinando reflexão e prática a serviço da educação dos estudantes, de modo a exercitar experiências diferenciadas de escuta, de silêncios produtivos, de viagens de pensamento e de ação (LARROSA, 1999).

Ainda por intermédio de Giroux (1997), pudemos conceber a pedagogia e o currículo por meio da noção de política cultural. É dentro do currículo que são construídos significados e valores culturais. Diferente da racionalidade técnica, o currículo é concebido como território em que se criam significados sociais e culturais em constante disputa e não somente como um processo de transmissão de fatos e de conhecimentos objetivos. Os significados criados são impostos, mas também podem ser contestados e desconstruídos. 
A partir de todos ideários que desconstroeme esses fios indisciplinados, imprimem resistência frente definimos como objetivo a compreensões cristalizadas maior deste artigo, analisar o discurso predominante exercitado por professora/ es do segundo segmento do Ensino fundamental, no componente curricular de Língua Portuguesa, observando aspectos sociais, culturais e pedagógicos, a partir das narrativas de acadêmico/asem formação para a docência na Universidade Federal do Acre.

0 texto tem caráter descritivo analítico, com o propósito de desnaturalizar situações observadas, resistindo e deslocando o sentido predominantede que $o$ vivenciado nas escolas deve-se orientar exclusivamente pelas políticas públicas de currículo e de avaliação em vigência no país. Fazer perceber ainda, que o observado nas escolas não acontece desde sempre, mas que é datado e produzido por discursos contemporâneos que têm transitado em seu entorno e que outras possibilidades são possíveis, a partir de

que impedem a criatividade.

Assim, não temos a pretensão de oferecer soluções práticas ao que é narrado. No entanto, entendemos que as análises sobre fenômenos complexos observados no âmbito das salas de aula, lançam flechas de compreensões, que ao se cruzarem com diferentes experiências podem possibilitar outros desdobramentos e outras interpretações sobre o que é construído nos espaços da educação básica, produzindo práticas alternativas com a diversidade que adentra as escolas (CORAZZA, 1996).

Como professora da disciplina Organização Curricular e Gestão da Escola, no Curso de Licenciatura de Letras Português da UFAC, que tem o propósito de discutir problemáticas contemporâneas dos currículos e das gestões das escolas da educação básica, solicitamos aos discentes que narrassem, com riqueza 
de detalhes, as práticas do/ as professore/as e atitudes do/as aluno/as, durante as aulas observadas nos período de realização do Estágio Supervisionado I, recentemente concluído, de modo que tais narrativas funcionassem como atividade de articulação/ correlação do que discutíamos teoricamente como que foi observado durante os dias em que estiveram vivenciando o cotidianodas salas de aula das escolas do Ensino Fundamental II.

A partir dessa solicitação, foram produzidas dezenove narrativas escritasque subsidiaram as discussões em aula e que diante da riqueza do material, extraímos quatro fragmentos, considerados importantes para analisar e compreender interpretações diferenciadas que ocorrem no momento contemporâneo, subsidiando a escrita do artigo que ora tornamos público. Os sujeitos produtores das narrativas sãoacadêmicos do quinto período do curso de Letras Português, identificados pelo primeiro nome, com informações complementares expostas em nota de rodapé. Para as análises, além dos fios de conhecimentos que têm nos orientado atualmente, dialogamos comoutros pensadores de diferentes campos, uma vez que a nossa perspectiva envereda por caminhos rizomáticos, não lineares, buscando transitar por veredas que contribuem com a construção do mosaico interpretativo, ou seja, metodologicamente transitamos de forma transdisciplinar. Diante desse panorama, conversamos também com Possenti (1995 e 1996) e Popkewits e Lindblad (2016).

Dessa conversa, afirmamos que as práticas pedagógicas desenvolvidas nas escolas, as quais originaram os fragmentos, representam a lógica de pensamento orientado em apenas uma variedade da Língua Portuguesa e na fundamentação populacional, que tem como tecnologia os conhecimentos estatísticos. 
Enfatizamos ainda, que essa lógica de raciocínio vem sendo fomentada desde as últimas décadas do século passado e que, paulatinamente, tem se firmado e se distanciado das peculiaridades diversas dos alunos das salas observadasdo Ensino Fundamental II, das quais tratam as narrativas.

\section{Os fios do discurso das políticas públicas de currículo e de avaliação: produção de identidades docentes}

Como afirmamos anteriormente, a análise que nos propomos realizar partiu de quatro fragmentos significativos que transcrevemos a seguir:

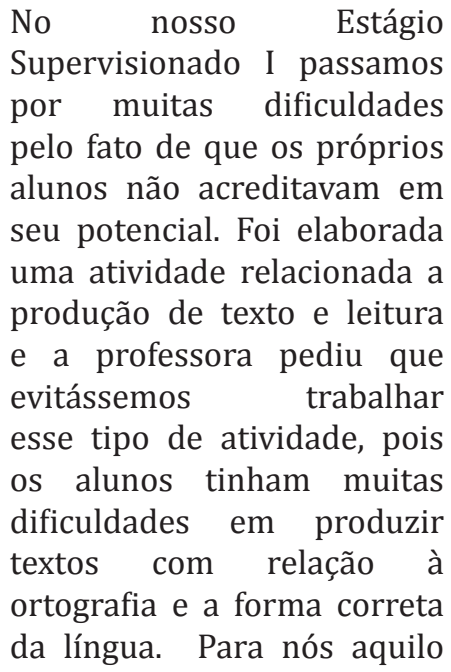

se tornou um desafio pois quando se trata da questão do ensino é necessário ensinar para a aprendizagem e não só para reproduzir e memorizar conteúdos. Diferente da expectativa da professora, a turma interagiu bem e ao final do estágio produziu textos no gênero fábula, de forma que a professora regente se surpreendeu com os resultados. A escola preocupada em produzir altos índices de resultados acaba restringindo outras possibilidades ${ }^{3}$.

Durante o Estágio SupervisionadoI,emconversa com nossa preceptora foi relatado um caso em que a Secretaria Municipal de Educação enviara uma prova para analisar o índice de desenvolvimento dos alunos, na área de Língua Portuguesa, no qual o texto base era poemas. Os resultados não foram satisfatórios, pois os alunos do $7^{0}$ período, até então, nunca tinham entrado em contato com poemas. A diretora na tentativa de melhorar os resultados pediu à secretaria que enviassem outra prova, só que dessa vez com a temática fábula, textos já estudados pelos alunos. Situação essa um tanto assustadora, pois a escola ao invés de se adequar às necessidades reais dos alunos, procurou

3 Fragmento da narrativa da aluna Francisca do Nascimento Almada, do 5o período do curso de Letras: Português - UFAC. 
favorecer exclusivamente resultados para provar que os parâmetros determinados para aquela série, que tentam homogeneizar os alunos, estão sendo seguidos e gerando os resultados esperados ${ }^{4}$.

Observamos durante o Estágio I, que ocorreu numa escola de periferia, com alunos do 6음 ano, o quanto problemas sociais afetam diretamente a aprendizagem dos alunos. A escola recebe crianças de lares desfeitos, em situação de risco, relacionados com o crime e drogas. A professora foi receptiva e pediu que continuássemos com 0 assunto iniciado por ela. Eram usados os descritores com temas pré-estabelecidos e o livro didático. Ao pedirmos aos alunos, após as nossas explicações, que fizessem uma atividade, percebemos o quanto a turma em geral tinham dificuldades, cometeram erros primários, eram quase analfabetos. Como nos foi dado uma certa liberdade e por orientação do nosso professor de estágio, modificamos a nossa segunda aula. 0 texto que foi dado como atividade na aula anterior era um bilhete. Partindo dos próprios erros dos alunos, trabalhamos ortografia, mas não seca. Pedimos que os alunos observassem as palavras grafadas erroneamente, cujas palavras tínhamos escrito no quadro e pedimos que eles corrigissem, quando não conseguiam, nós ensinávamos, contextualizadas em seus textos. Esse trabalho de parar o conteúdo e revisar algo que deveria ter sido aprendido anteriormente, normalmente não acontece. A professora nos disse que dava as sequências didáticas que lhes eram passadas. Os alunos que não conseguiam acompanhar ficavam de lado ${ }^{5}$.

Durante o estágio, em uma turma de $6^{\circ}$ ano, foi observada a nítida dificuldade de leitura e escrita, por exemplo. É evidenciada a disparidade entre o que é planejado e o que é efetivamente necessitado pelos alunos. 0 maior foco do planejamento da professora preceptora é a transmissão do conteúdo prescrito para a série, definido para cada bimestre. Não é levada em consideração a necessidade de superar dificuldades dos alunos ${ }^{6}$.

A partir dos fragmentos transcritos das narrativas de

4 Fragmento da narrativa da aluna Luana Karolyne dos Santos,do 5o período do curso de Letras: Português-UFAC.

5 Fragmento da narrativa da aluna Daniela Rodrigues de Melo Oliveira, do 5o período do curso de Letras: Português-UFAC.

6 Fragmento da narrativa da aluna Naiane Moreira da Silva, do 5ำ período do curso de 
quatro estagiárias, observamos dois aspectos que representam na atual conjuntura as identidades da professora e dos alunos, produzidas pelo discurso da política de avaliação do Ministério de Educação brasileiro. Tal política, a nosso ver, induz posturas e formas de agir, que levam a resultados estatísticos classificatóriosdas escolas como boas ou ruins, mas que por outro lado, inibem a ampliação de possibilidades que conduzam ao encontro das necessidades subjetivas dos alunos. Dessa compreensão, permeiam duas vertentes de análises que carecem ser explicitadas. A primeira decorre da compreensão que temos do processo de formação da identidade docente e a segunda diz respeito à fundamentação estatística, que orienta a política atual de avaliação do Ministério da Educação, que fundamentalmente tem orientado os discursos e as práticas pedagógicas, desancoradas das origens sociais e culturais dos alunos. a primeira vertente, nos aproximamos de Hall, que, em sua abordagem, coloca a cultura como elemento central para compreendermos os aspectos múltiplos da vida contemporânea. Para ele, a formação daquilo que nomeados de nossas identidades poderia ser adequadamente conceituado como as posições que adotamos para viver socialmente e que com o decorrer do tempo vão se solidificando ao ponto de parecer que emergem de dentro dos sujeitos como parte integrante e acabada, mas que foram ensejadas por um complexo agrupamento de particularidades, significações, "sentimentos, histórias e experiências únicas e peculiarmente nossas, como sujeitos individuais" (HALL, 1997, p. 26). Ou seja, aponta que as identidades são constituídas na interação com as culturas, às quais vamos tendo a oportunidade de transitar.

Assim, em diálogo produtivo com Hall, entendemos que as identidades sociais são

Para enfatizarmos sobre Letras: Português-UFAC. 
construídas no interior das representações, por meio da cultura e não fora dela, de modo que elas (as identidades) são resultantes de um processo de absorção e aceitação subjetiva. Tal concepção permite que nos coloquemos no interior das identificações dos discursos culturais exteriores, que chegam até nós no trânsito da vida, nos abastecendo e por permissão consciente ou inconscientemente nos subjetivemos dentro deles. Dessa forma, as nossas subjetividades, são produzidas parcialmente pelos discursos, de forma dialógica.

Nos quatrofragmentos transcritos, é possível observar que a cultura escolar dessas instituições observadas, está completamente permeada pelo discurso da política de resultados que constituem as avaliações externas. É perceptívelo quanto essas políticas de resultados têm induzindo práticas pedagógicas massificadas,

orientadas por descritores prescritivos. Quandoédito que“a escola [está] preocupada em produzir altos índices de resultados [e], por isso, acaba restringindo outras possibilidades", entendemos que o processo de ensino que é desenvolvido pela escola, por intermédio dessas professoras, incorporou, aos seus modus operandi, procedimentos mais objetivados que possam levar com mais efetividade a resultados positivos, cobrados em momentos das avaliações externas direcionadas aos alunos do Ensino Fundamental II. A preocupação da professora, narrada por Francisca, está voltada para a escrita das palavras e a forma "correta" de utilização da língua escrita, muito alinhada à norma padrão, ou melhor, o seu trabalho com a Língua Portuguesa está voltado para o que está prescrito na(s) gramática(s) da língua que coincide com os descritores que orientam as avaliações externas.

De acordo com Possenti (1995), podemos afirmar que há um conceito de gramática compatível para cada conceito formulado e entendimento 
do que seja língua. Ao fazer essa afirmação, esse linguista brasileiro exemplifica três conceitos de língua, que daí decorre os conceitos de gramática. Ele Inicia expondo aquela compreensão de língua que visualiza apenas uma das variedades linguísticas, frente à diversidade utilizada pela comunidade; recobre somente aquele seguimento de pessoas que agrega em seu uso social, formas de falar e escrever considerada culta.

Nessa perspectiva, qualquer variante da língua que não esteja comportando expressões moldadas por esse parâmetro é considerado errado e por assim ser, fora da língua. Essa forma elitista de conceituação de língua erra por excluir variantes culturais, pelo poder que detém e por preconceito ao diferente, justificando a exclusão por padrões unificadores, expressos na gramática normativa que tentam uniformizar, mas sem grande sucesso.

Embora já seja do nosso conhecimento que as línguas se alteram; que sofrem mudanças ao longo do tempo, essa gramática que abarca apenas a variante historicamente considerada culta, faz vista grossa a essa realidade constatada. Mas mesmo com essa dureza de percepção, ela mesma, de tempos em tempos, embora tardiamente dobrase às alterações, mas única $\mathrm{e}$ exclusivamente motivada pelas inovações dos ícones da escrita, ou melhor, pelas alterações produzidas pelos considerados "bons escritores", que introduzem em seus escritos outras formulações até então não consideradas.

Outro exemplo de compreensão da língua é equivalente a um construto teórico, o qual se conforma abstratamente. Nessa compreensão, seus observadores/propositores preveem por antecipação sistemas coexistentes, mas não os incorporam, uma vez que não é previsto variação, isso porque embora trabalhem a partir dos enunciados das falas e de suas flutuações, continuam 
entendendo o sistema sem possibilidades de modificações, mesmo que não validem preconceitos diante de qualquer variante linguística, o sistema permanece sem variação. A gramática Gerativa, decorrente dessa compreensão de língua "só considera enunciados ideais produzidos por um falante ideal que pertença a uma comunidade linguística ideal. Além disso, concebe a língua como espelho do pensamento, o que implica fazer uma semântica de base lógica privilegiando o valor de verdade dos enunciados" (POSSENTI, 1995, p. 79, entendimento que exclui todas as outras funções da linguagem.

Por último, e ao nosso olhar mais congruente com o que defendemos, língua é o agrupamento das variedadesque uma determinada comunidade utiliza, declarada e reconhecida como diferentes, mas de significação correspondente no âmbito de um mesmo idioma. Essa conceituação parte da concepção de que os falantes não exprimem o pensamento por uma língua uniforme e não falam a partir de uma única maneira. Utilizam formas diversas entre si, mas constituem a mesma língua, com a sensação de pertencimento e de falante da mesma língua. Esse sentimento de pertença a uma língua conflui para as variedades que não estão reclusas às regras gramaticais e aos seus traços linguísticos internos. A sensação de pertencimento dos falantes usuários da língua e que se sentem falando a mesma língua, apesar das diferenças, é o acento que recai a maior influência nesse contexto.

Diante

desses esclarecimentos, voltemos às preocupações das professoras observadas do Estágio Supervisionado. Se os alunos são avaliados por instrumentos elaborados por sujeitos estranhos ao processo de ensino, pelos quais coletam informações a respeito das aprendizagens e que têm indicado pelos índices estatísticos que a educação escolar do município 
de Rio Branco tem avançado na escala classificatória, isso tem reforçado convicções que conformam as identidades profissionais de alguns professores.

Se o Índice de Desenvolvimento da Educação Básica - IDEB do município de Rio Branco indica a escalada crescente de melhoria a cada processo avaliativo, verificáveis em seus resultados, porque esses alunos dessas escolas observadas apresentam tantas dificuldades para escrever um pequeno texto que expresse de forma articulada o seu pensamento? Será que é o ensino da gramática descontextualizada que têm levado a resultados satisfatórios nessas avaliações? Estando os professores cientes dos sinais de baixa efetividade na produção textual, porque ainda assim, persistem com a crença nos resultados estatísticos?Sem exceção, foi narrado que os alunos do $6^{\circ}$ e e $7^{\circ}$ anos do Ensino Fundamental II, respectivamente, detêm muitas dificuldades de oralidade e de escrita, porque que ainda assim, os descritores indutivos das atuais práticas pedagógicas continuam reinando incólumes?

Não temos respostas para essas problematizações, mas visualizamos alguns indícios que podem sugerir pequenos fios explicativos, a partir do pensamento estatístico construído na modernidade, diante das posturas de alguns professores que se mostram intransigentes e indispostos a repensar o seu modus operandi, frente ao que assistem em seus alunos.

o trabalho curricular direcionado "a mentes semdomicílio"7

Seguindo a trilha de Popkewitze Lindblad (2016), afirmamos que as avaliações extensivas fazem parte de mecanismos procedimentais para o controle e governamentalidade das populações escolarizáveis e dos agentes que atuam nas esferas educacionais. Tais avaliações produzem relatórios quantitativos e classificatórios,

7 "A mente sem-domicílio" é uma expressão extraída de Popkewitz Lindblad (2016). 
apoiados amplamente na mecânica da estatística, que convidam a comparações entre estados, municípios, escolas e sujeitos. 0 conhecimento estatístico, a partir do séculoXIX, começou a ser utilizado como ferramenta estatal que tornou possível definir qualidades e características da humanidade em categorias populacionais, as quais permitiram "pensar, ver, agir e sentir sobre a mudança de condições sociais e, embora não seja muitas vezes considerado, mudar pessoas" (POPKEWITZ e LINDBLAD, 2016, p. 731). Dessa forma, essa mecânica/ tecnologia estatística passou a viabilizar o planejamento para o "progresso", como também o planejamento de pessoas, sobrepondo diferenças relacionadas à política e à cultura da vida cotidiana. Nesse sentido, a diversidade de característica de crianças, jovens e adultos é liquefeita (BAUMAN, 2001) em categorias populacionais, independente das diferenças históricas, sociais e culturais, tomando como dado para o cálculo estatístico a idade e características condensadas, transformandoas em dado objetivo para o controle populacional.

Se nos voltarmos para a educação escolarizada, idade dos sujeitos e série escolar, sobreposto às características sociais, as escolas passaram a ser organizadas e pensadas a partir de determinadas categorias populacionais, subsumindo as diferenças dentro dessas mesmas categorias, como escola urbana, escola rural, crianças e jovens em situação de risco, aluno desfavorecido, aluno com dificuldade, desempenho escolar, aluno em defasagem idade/série etc., tornando a diversidade em categorias liquefeitas e objetivas.

Esse raciocínio, a partir de categorias populacionais, não é utilizado apenas para a gestão estatal; ele está, também, permeando o pensamento dos professores, gestores, coordenadores pedagógicos em relação à gestão do currículo no cotidiano educacional. Quando se fala nas secretarias de educação, nas escolas, nas equipes pedagógicas, 
dos não saberes, das dificuldades de aprendizagem, defasagem idade/série, alunos indisciplinados, por exemplo, estão incorporando a fundamentação das categorias populacionais, que ajustam os problemas e as suas causas.

As políticas públicas educacionais são criadas para direcionar o olhar dos gestores e professores para os focos que se deseja intensificar e com elas, acompanham um aparato organizacional e instrucional de acordo com o alvo que se pretendeatingir.Tomemoscomo exemplo, a política de avaliação externa que atualmente vem concentrando seu foco em uma determinada direção, levando os agentes escolares a desenvolverem certo tipo de prática pedagógica, como é repetidamente expressado nos fragmentos inicialmente descritos.

É uma política que tem como alvo a verificação da aprendizagem ao final dos vários segmentos da educação básica e dessa forma, é o que tem dado o tom do que se exercita

na escola. A população-alvo são 5ㅜㅜ 9o e $3^{\underline{0}}$ anos da educação básica, mas como essa política está articulada com outrasque classificam a escola como ela mesma, toda a dinâmica que se exercita, em relação ao ensino aprendizagem está umbilicalmente relacionada a ela.Descritores decompetências e livros didáticos são definidos, passando a serem os únicos materiais de desenvolvimento das aulas, embora se coloque um simulacro de liberdade da escola, o que tem de fato erigido o seu funcionamento são esses instrumentos, independente de serem eles os mais adequados para as características peculiares do alunado.

Isso ocorre dessa forma, porque a lógica de pensamento, tanto das políticas públicas, quanto do pessoal que está mais próximo dos alunos, é orientada pelas categorias populacionais que dissolvem as diferenças individuais em um grande bloco categórico. 0 trabalho pedagógico em sala de aula obedece à mesma lógica, elegendo uma variação didática 
e uma variação da língua, a mais prestigiada, para encaminhar todo o desenvolvimento de ensino. Os sujeitos, para os quais os procedimentos didáticos não se adequam e que culturalmente estão fincados em outras variações da língua, são categorizados como alunos com dificuldades de aprendizagens, como pouco dotados intelectualmente, desfavorecidos e muitas outras categorias que justificam a não alteração de suas práticas, embasados principalmente pelo tempo único que é definido para todos os sujeitos, independente de suas características; conduta que contribui para o melhor controle da população escolarizada.

Segundo Popkewitz e Lindblad, a utilização da fundamentação populacional tem sido proeminente nas últimas décadas, se efetivando principalmente por meio das avaliações extensivas, expandindo-se radicalmente no ocidente para a formulação de políticas direcionadas para os mais diversos segmentos populacionais. Dizem ainda, que essa fundamentação...

tem desempenhado um papel viral na determinação de diferenças de desempenho definidas entre grupos taxonômicos, as quais servem para delinear o sistema educacional de um país, em termos de gênero e origem social ou geográfica. As diferenças são comparadas com características sociais, institucionais e de gestão dos sistemas de ensino, a fim de analisar a razão de tais disparidades da educação, na cultura ou na sociedade, bem como nas características individuais e de direcionamento de carreira (POPKEWITZ; LINDBLAD, 2016, pp. 732-733).

Assim, essa forma de raciocínio, que utiliza a fundamentação populacional, é decodificada em discurso educacional para "diminuir" déficits educacionais. Isso significa que números e categorias adentram com ímpeto os espaços escolares, possibilitando classificações, normalizações e separações. A quantificação que leva às categorias implica um "sem domicílio", que envolve abstrações sobre a existência humana, "que parece não 
ter um lugar histórico, uma especificidade cultural ou limites geográficos" (POPKEWITZ;

LINDBLAD, 2016, p. 739). A fundamentação estatística permitiu colocar em um único arcabouço, padronizando fenômenos de atributos dispersos em sociais e econômicos da população. Por meio da abstração da sociedade, da cultura e da economia, os alunossão identificados ehomogeneizados para a formulação de políticasimplementadaspara corrigir ou desviar formas indesejadas de atuação, ou seja, para o controle dessas populações em determinadas direções.

Essas formas de controle, em que se aliam práticas sociais desejadas com números e populações, seguem na contramão da produção de ambientes que favoreçam sentimentos de pertença. A quantificação possibilita a classificação, a abstração de si e autilização de linguagem comum e universal, por outro lado,distanciadosocialimediato e do local da sala de aula. "A mente sem domicílio" é feita por números e a sua principal tecnologia de construção é a estatística, uma vez que agrega as pessoas/alunos em categorias transcendentais, desconhecendo a sua origem histórica e cultura particular, homogeneizando todos em um único guarda-chuva categorial.

Para concluir, enfatizamos que os fragmentos de observações das alunas estagiárias do quinto período do curso de Letras Português da UFAC, que evidenciam a prática de ensino das professora/es das escolas do município de Rio Branco, representam a lógica de pensamento fundamentado em uma variedade da Língua Portuguesa e da fundamentação populacional, que tem como tecnologia os conhecimentos estatísticos. Enfatizamos ainda que essa lógica de raciocínio vem sendo fomentada desde as últimas décadas do século passado e que, paulatinamente, vem se firmando e moldando as identidades profissionais das professore/as e ao mesmo 
tempo, vem se distanciando das peculiaridades diversas do/as aluno/as das escolas observadas.

Apesar de toda a indução provocada pelas avaliações externas, que solidificam pensamentos homogêneos, ainda assim, éna figura do/a professor/a que tem recaído as principais críticas pelo insucesso das não aprendizagens dos alunos que passam pela escola, como bem quiseram induzir as estagiárias do Curso de Letras nas discussões das nossas aulas. Desconstruir tais percepções, fazendo-as visualizar outros aspectos que contribuem para essa situação, ao nosso olhar, ilustram possibilidades de resistência ao que nas últimas décadas vem orientando $\mathrm{e}$ constituindo a cultura escolar, as identidades docentes e suas práticas pedagógicas.

\section{Referências}

ALVES, N. Sobre movimentos das pesquisas nos/dos/com os cotidianos. In.: ALVES, N.; OLIVEIRA, I. B. (Orgs.). Pesquisa nos/dos/com os cotidianos das escolas: sobre redes e saberes. Petrópolis: DPetAlli, 2008.
BAUMAN, Z. Modernidade Líquida. Tradução de Plínio Dentzien. Rio de Janeiro: Jorge Zahar Editora, 2001.

CORAZZA, S. M. Labirintos da pesquisa, diante dos ferrolhos. In: COSTA, M. V. Caminhos investigativos. Porto Alegre: Mediação, 1996.

FAZENDA, I.

Interdisciplinaridade: qual o sentido? São Paulo: Paulus, 2006. FOUCAULT, M. Microfísica do poder. Organização e tradução de Roberto Machado. Rio de Janeiro: Edições Graal, 2007.

GALLO, S. Transversalidade e formação de professores. In: RIVERO, C. M. L. e GALLO, S. A formação de professores na sociedade do conhecimento. Bauru-SP: Edusc, 2004.

GARCIA, R. L. Da fronteira se pode alcançar um ângulo de visão muito mais amplo... embora nunca se veja tudo. In: Ensinar e aprender: sujeitos, saberes e pesquisa. Encontro Nacional de Didática e Prática de Ensino - ENDIPE. Rio de Janeiro: DP\&A, 2000.

GIROUX, H. A. Os professores como intelectuais: rumo a uma pedagogia crítica da aprendizagem. Porto Alegre: Artmed, 1997.

GIROUX, H. A. Teoria crítica e resistência em educação. Petrópolis: Vozes, 1986.

HALL, S. A centralidade da cultura: notas sobre as revoluções de nosso tempo. In: Educação \& Realidade, v. 22, n. 2, 1997, pp. 
15-46.

LARROSA, J. Tremores: escritos sobre experiência. Tradução de Cristina Antunes e João Wanderley Geraldi. Belo Horizonte: Autêntica Editora, 2015.

LARROSA, J. Pedagogia profana: danças, piruetas e mascaradas. Tradução de Alfredo Veiga-Neto. Belo Horizonte: Autêntica, 1999. PESSOA, V. I. F. Currículo e interdisciplinaridade na formação de professores. Rio Branco-Ac: Edufac, 2016. POPKEWITS, T. e LINDBLAD, S. A fundamentação estatística, o governo da educação e a inclusão e exclusão sociais. In: Educação
\& Sociedade. Campinas, v. 37, n. 136, jul./set., 2016, pp. 727-754. POSSENTI, S. Gramática e política. In: ABREU, M. Leituras do Brasil: antologia comemorativa pelo $10^{\mathrm{o}}$ Cole. Campinas, SP, Mercado de letras, 1995.

POSSENTI, S. Por que (não) ensinar gramática na escola. Campinas-SP, ALB: Mercado de letras, 1996.

Data de recebimento: 22/10/2017 Data de aceite: $26 / 12 / 2017$ 